\title{
Stilbene analogues affect cell cycle progression and apoptosis independently of each other in an MCF-7 array of clones with distinct genetic and chemoresistant backgrounds
}

\author{
YVONNE BADER $^{1}$, SIBYLLE MADLENER ${ }^{1}$, STEPHAN STRASSER ${ }^{1}$, SUSANNE MAIER $^{1}$, \\ PHILIPP SAIKO $^{2}$, NICOLE STARK ${ }^{1}$, RUXANDRA POPESCU $^{1,3}$, DANIELA HUBER $^{1}$, \\ MICHAELA GOLLINGER ${ }^{1}$, THOMAS ERKER ${ }^{4}$, NORBERT HANDLER ${ }^{4}$, AKOS SZAKMARY ${ }^{1}$, \\ WALTER JÄGER ${ }^{4}$, BRIGITTE KOPP ${ }^{3}$, IOANNIS TENTES ${ }^{5}$, MONIKA FRITZER-SZEKERES ${ }^{2}$, \\ GEORG KRUPITZA $^{1}$ and THOMAS SZEKERES ${ }^{2}$ \\ ${ }^{1}$ Institute of Clinical Pathology, ${ }^{2}$ Clinical Institute of Medical and Chemical \\ Laboratory Diagnostics, General Hospital of Vienna, Medical University of Vienna; \\ Departments of ${ }^{3}$ Pharmacognosy and ${ }^{4}$ Pharmaceutical Chemistry, Faculty of Life Sciences, \\ University of Vienna, Vienna, Austria; ${ }^{5}$ Department of Biochemistry, Medical School \\ Democritus University of Thrace, Alexandroupolis, Greece
}

Received October 4, 2007; Accepted November 9, 2007

\begin{abstract}
The development of chemoresistant breast cancer is poorly understood and second treatment options are barely investigated. The term 'chemoresistance' is ill-defined and thus, our experimental analyses aimed to disentangle the resistance to cell cycle arrest from the resistance to trigger apoptosis, both of which are important mechanisms to be targeted by anticancer therapy. Therefore, an MCF-7 array, which encompassed clones harboring distinct geneticallyand pharmacologically-induced stages of resistance, was established. For this, MCF-7 cells were stably transfected with erbB2 cDNA and a dominant negative p53 mutation and the two clones were subjected to long-term treatment with the clinical agents 2'-deoxy-5-fluorouridine (5-FdUrd) or arabinosylcytosine (AraC) to develop specific chemoresistance. This array was tested with 3,4',5-trihydroxy-transstilbene (resveratrol) and the methoxylated paired stilbene
\end{abstract}

Correspondence to: Professor Thomas Szekeres, Clinical Institute of Medical and Chemical Laboratory Diagnostics, General Hospital of Vienna, Medical University of Vienna, Waehringer Guertel 18-20, A-1090 Vienna, Austria

E-mail: thomas.szekeres@meduniwien.ac.at

Professor Georg Krupitza, Institute of Clinical Pathology, Medical University of Vienna, Waehringer Guertel 18-20, A-1090 Vienna, Austria

E-mail: georg.krupitza@meduniwien.ac.at

Key words: breast cancer, chemoresistance, erbB2, methoxylated resveratrol analogue, p53 analogue 3,4',5-trimethoxy-trans-stilbene (M5) to investigate whether these agents can overcome genetically- and pharmacologically-induced chemoresistance and to correlate the structure-activity relationship of resveratrol and M5. In all conditions tested, M5 exhibited stronger anticancer activity than resveratrol, but the cell cycle inhibitory properties of the tested drugs were dependent on the genetic background and the chemoresistant phenotype. In contrast, the proapoptotic properties were rather similar in the distinct genetic backgrounds of the clone array and therefore, apoptotic triggers and cell cycle checkpoints were distinctly affected and are thus independent of each other. The study demonstrates the merits or virtues of the genotypically- and phenotypicallydefined clones of the MCF-7 array as a testing tool for novel drugs, which discriminates the two types of chemoresistance mechanisms.

\section{Introduction}

Worldwide, breast cancer is the most common form of cancer in females, and it is the second leading cause of cancer deaths after lung cancer among women (1). It affects $\sim 1$ out of 8 women at some stage of their life in the Western world. There are several prognostic factors associated with breast cancer, the most prominent being the presence of estrogen and progesterone receptors in the breast cancer cell (hormone receptor positive breast cancer is usually associated with a much better prognosis as compared to hormone negative cancer), or HER2/neu (ErbB2) status and expression of the mutated p53 (mtp53) tumor suppressor gene. Patients whose cancer cells are positive for HER2/neu suffer from more aggressive disease and are prone to develop resistance to chemotherapy with limited second treatment options. 
Therefore, new agents which overcome chemo-resistance need to be discovered. For this we generated an MCF-7 breast cancer array consisting of clones overexpressing erbB2 cDNA or harboring a dominant negative mtp53 and of clones with specific chemoresistance to 5-FdUrd (2'-deoxy-5fluorouridine) and to AraC (arabinosylcytosine). This investigation evaluated whether this clone array is a useful tool for the testing of novel lead compounds that may override chemoresistance. We chose resveratrol (3,4',5-trihydroxytrans-stilbene) and the methoxylated derivative M5 (3,4',5trimethoxy-trans-stilbene) to study the structure-activity relationship in chemoresistant MCF-7 breast cancer cells with distinct genetic backgrounds.

Resveratrol is classified as a phytoestrogen due to its structural similarity to the estrogenic agent diethylstilbestrol (2). It shows estrogenic activity in mammals, activates the transcription of estrogen-responsive reporter constructs $(3,4)$ and has been reported to exhibit both anti-carcinogenetic and cardio-protective activities which may be attributed to its antioxidant and anti-coagulant properties $(5,6)$. In animal experiments resveratrol reduced the incidence of carcinogeninduced development of cancer $(7,8)$ and was shown to inhibit tumor initiation, promotion and progression (8). It is capable of inducing differentiation and apoptosis in a multitude of tumor cell lines, such as human leukemia-, colon-, breast-, prostateand esophageal cancer cells (9-14) and causing cell cycle arrest in the $\mathrm{S}$ and $\mathrm{G} 2$ phase (15) in part due to the inhibition of ribonucleotide reductase which catalyzes the rate-limiting step of de novo DNA synthesis (16).

Resveratrol has been found in high concentrations in a wide variety of plants, including traditional oriental medicinal plants (17). Relatively high concentrations of resveratrol are also present in grape juice and, especially, in red wine. The biological activity of resveratrol and its analogues such as piceatannol depends significantly on the structural determinants (18) and it has been shown that methoxylated stilbene derivates show effects which are different from their nonmethoxylated forms. When tested in the Fas-ligand-resistant lymphoma cell lines HUT78B1 and HUT78B3 and the multidrug-resistant leukemia cell lines HL-60-R and K562-ADR, 3'-hydroxypterostilbene (3,5-dimethoxy analogue of piceatannol) induced apoptosis, whereas piceatannol and resveratrol did not (19). In our investigation the methoxylated resveratrol analogue M5 exhibited a stronger activity than resveratrol even in chemoresistant cancer cells.

This investigation did not aim to elucidate mechanisms of drug action or of chemoresistance acquisition but intended to show that different drugs induce distinct types of resistance in distinct genetic backgrounds. Therefore, the clone array is helpful in discovering novel leads for the treatment of specific resistance parameters. MCF-7 cells were found to detect the vast majority of those agents which exhibit anticancer activity in the 60 cancer cell line screen of the National Cancer Institute (NCI) $(20,21)$. This underscores the significance of the results obtained with the MCF-7 clone array presented here.

\section{Material and methods}

For easier readability we abbreviated the genotypes as follows: M, MCF-7 cells; RF.M, 5-FdUrd resistant MCF-7 cells; RA.M, AraC resistant MCF-7 cells; M[erbB2], MCF-7 cells overexpressing erbB2; M[mtp53], MCF-7 cells harboring mutated p53; RF.M[erbB2], 5-FdUrd-resistant MCF-7 cells overexpressing erbB2; RF.M[mtp53], 5-FdUrdresistant MCF-7 cells harboring mutated p53; RA.M[erbB2], AraC-resistant MCF-7 cells overexpressing erbB2; RA.M[mtp53], AraC-resistant MCF-7 cells harboring mutated p53 and M[mock], the control cell line, transfected with an empty vector.

Chemicals. Resveratrol, 5-FdUrd and AraC were from Sigma. The methoxylated resveratrol analogue 3,4',5-trimethoxytrans-stilbene (M5, see chemical structures below) was synthesized using standard chemical methodologies. Methoxylated diethyl benzylphosphonate $(10 \mathrm{mmol})$ was cooled to $0^{\circ} \mathrm{C}$ under argon in a flame-dried three-neckedflask. Then $10 \mathrm{ml}$ dry DMF, sodiummethoxide (1.12 g, 20 mmol) and methoxylated benzaldehyde $(10 \mathrm{mmol})$ was added. The mixture was stirred at room temperature for $1 \mathrm{~h}$ and heated to $100^{\circ} \mathrm{C}$ under argon for $1.5 \mathrm{~h}$. The solution was poured into $250 \mathrm{ml}$ of ice water, the precipitate was filtered off and re-crystallized from ethanol to yield white crystals (22).<smiles>Oc1ccc(/C=C/c2cc(O)cc(O)c2)cc1</smiles>

3, 4', 5-trihydroxy-trans-stilbene (resveratrol)<smiles>COc1ccc(/C=C/c2cc(OC)cc(OC)c2)cc1</smiles>

3, 4', 5-trimethoxy-trans-stilbene (M5)

Cell culture. The human breast carcinoma cell line MCF-7 was grown in Dulbecco's modified Eagle's medium (DMEM) containing $10 \%$ heat-inactivated FCS , $1 \%$ penicillinstreptomycin and 1\% Glutamax (all from Gibco, Invitrogen). $\mathrm{M}$ [erbB2] and M[mtp53] (cells transfected with full-length erbB2 or mutated-p53 cDNA) and chemoresistant RF.M[mtp53], RA.M[mtp53], RF.M[erbB2] and RA.M[erbB2] were grown in the above-described medium including $400 \mu \mathrm{g} / \mathrm{ml} \mathrm{G}-418$ sulphate (Gibco, Invitrogen) to maintain the selection pressure. Moreover, chemoresistant cells were exposed to $500 \mathrm{nM} 5$-FdUrd or AraC, respectively. All cells were incubated at $37^{\circ} \mathrm{C}$ in a humidified atmosphere containing $5 \% \mathrm{CO}_{2}$. 
Transfection of cells. M cells were plated into 60-mm dishes and grown for 2 days until 40-50\% confluence. Lipofection of cells with mtp53 cDNA (plasmid pLTRp53cGval153 containing a chimera of mouse p53 cDNA and genomic DNA with introns 2-9 controlled by the 5'LTR of Harvey murine sarcoma virus) together with a neomycin resistance gene (pCI-neo) yielded the pooled mtp53 clone. ErbB2 fulllength cDNA was first subcloned from pC6H6 into the MCS of pSPUTK with $N c o$ I and $X b a \mathrm{I}$, cut with Bsu361 and XbaI to remove the 3'UTR of erbB2, blunted with a Klenow fragment and religated. Then the complete erbB2 ORF was released from pSPUTK with HindIII and ClaI and ligated into the EcoRV site of pCDNA3.1/V5-HisB after removal of the overhangs with the Klenow fragment. The lipofection of this construct with Transfectam reagent (Promega) yielded the pooled erbB2 cell clones. Lipofection cells were washed once with pre-warmed DMEM without FCS. Five micrograms of DNA $(1 \mu \mathrm{g} / \mu \mathrm{l})$ and $10 \mu \mathrm{l}$ Transfectam were separately pipetted into $0.75 \mathrm{ml}$ DMEM each and then the two mixtures were combined. Transfectam-DNA complexes were allowed to form for $10 \mathrm{~min}$ and were then applied onto $\mathrm{M}$ cells for $3 \mathrm{~h}$ in a humidified incubator. The transfection was stopped by adding $4 \mathrm{ml}$ DMEM containing 10\% FCS. The following day, cells were split into new dishes with fresh medium and $48 \mathrm{~h}$ after transfection $800 \mu \mathrm{g} / \mathrm{ml} \mathrm{G}-418$ sulphate (for mtp53 and erbB2 cell clones) was added.

After 10-14 days the G-418 concentration was reduced to $400 \mu \mathrm{g} / \mathrm{ml}$ and the cells of each transfection were pooled for further experiments.

The induction of resistance. To establish resistance to 5-FdUrd the M[mtp53] and M[erbB2] clones were treated for a long time with increasing concentrations of 5-FdUrd. Cells were exposed to the initial concentration of $250 \mathrm{nM} 5$-FdUrd which was raised soon thereafter to $500 \mathrm{nM}$. The cells were kept under their current doses for 48-72 $\mathrm{h}$ and then left to recover before the next treatment cycle. After 10 months of treatment the cells were resistant to $500 \mathrm{nM} 5-\mathrm{FdUrd}$, at which point they were used for experiments.

To generate resistance, the AraC M[mtp53] and M[erbB2] clones were exposed to the initial concentration of $250 \mathrm{nM}$ and $5 \mu \mathrm{M}$ AraC. The $250 \mathrm{nM}$-treated cells were then exposed to $500 \mathrm{nM}$ for a period of 12 months until the establishment of resistance to $500 \mathrm{nM}$ AraC. The $5 \mu \mathrm{M}$-treated cells were exposed to reduced doses $(2.5 \mu \mathrm{M}-1 \mu \mathrm{M}-750 \mathrm{nM}$ and $500 \mathrm{nM}$ within 6 months), as the cells did not survive higher doses and were then treated with $500 \mathrm{nM}$ AraC for another 6 months until they were resistant. The cells were treated with their current concentrations for 72-96 h. Finally, the two cell types (250 nM and $5 \mu \mathrm{M}$ initial doses) were pooled and used for experiments.

Hoechst 33258 and propidium iodide double staining. To measure apoptosis in $\mathrm{M}$ clones, cells were seeded at a density of $1 \times 10^{4}$ in 24 -well plates, grown to $30 \%$ confluence and then 2, 10, 30 and $50 \mu \mathrm{M}$ resveratrol or M5 was added. Experiments were terminated after $96 \mathrm{~h}$ of treatment by collecting the culture supernatant and washing the attached cells with phosphate buffered saline (PBS, pH 7.2). This was followed by the trypsinization, administration of a new medium and
$10 \%$ FCS, and pooling with the collected supernatant cells. Then Hoechst 33258 (HO, Sigma) and propidium iodide (PI, Sigma) were added to the pooled cells (final concentration of 5 and $2 \mu \mathrm{g} / \mathrm{ml}$, respectively). After an incubation period of $1 \mathrm{~h}$ at $37^{\circ} \mathrm{C}$, the stained cells were examined under a Zeiss Axiovert 35 fluorescence microscope with a DAPI filter, photographed on Kodak Ektachrome P1600 film (Eastman Kodak Company, Rochester, NY, USA), analyzed and the viable, apoptotic and necrotic cells were counted manually. Hoechst 33258 dye penetrates intact membranes, stains the nuclear chromatin and, therefore, allows the monitoring of nuclear changes associated with apoptosis, such as chromatin condensation and nuclear fragmentation. Propidium iodide (PI), on the other hand, cannot cross intact membranes and is excluded from viable and early apoptotic cells. Consequently, the PI uptake indicates loss of membrane integrity, which is characteristic of necrotic and late apoptotic cells. Necrosis is characterized in this system by a nuclear PI uptake without a chromatin condensation or nuclear fragmentation. In combination with fluorescence microscopy, the selective uptake of the two dyes allows for the detection and discrimination of viable cells from those with apoptotic and necrotic phenotypes $(23,24)$. Experiments were performed in triplicate.

Growth inhibition assay. M array clones were seeded at a density of $1 \times 10^{4}$ in 24-well plates and grown for $24 \mathrm{~h}$ to $20 \%$ confluence. At this stage increasing concentrations (2, 20, 30 and $50 \mu \mathrm{M}$ ) of resveratrol and M5 were added for 24, 48 and $72 \mathrm{~h}$. Then cells were washed with PBS, trypsinized and counted with a cell counter (Sysmex Corp., Japan). Experiments were performed in triplicate.

Determination of doubling time (dt) and percent of cell division. Cells were seeded at a density of $1 \times 10^{4}$ in 24 -well plates and grown for $24 \mathrm{~h}$. At this stage they were treated with 2 concentrations (10 and $250 \mathrm{nM}$ ) of 5-FdUrd. Cells were trypsinized and counted three times during logarithmic growth (after 24, 48 and 72 h) with a cell counter (Sysmex Corp.). Experiments were performed in triplicate.

Doubling time was: $\mathrm{nd}=(\log \mathrm{c} 2-\log \mathrm{c} 1) / \log 2 ; \mathrm{dt}=\mathrm{pg} /$ nd; c1, first count; c2, second count; nd, number of doublings; $\mathrm{pg}$, period of growth in hours between $\mathrm{c} 1$ and $\mathrm{c} 2$; dt, doubling time and log, decimal logarithm (to the basis 10).

The determination of the percent cell division and of proliferation inhibitory concentration $\left(I_{p} C_{50}\right)$. The percent of cell division as compared to the untreated control was calculated as follows:

$\left[\left(\mathrm{C}_{72 \mathrm{~h}+\text { drug }}-\mathrm{C}_{24 \mathrm{~h}+\text { drug }}\right) /\left(\mathrm{C}_{72 \mathrm{~h} \text { - drug }}-\mathrm{C}_{24 \mathrm{~h} \text { - drug }}\right)\right] \times 100=\%$ cell division

$\mathrm{C}_{72 \mathrm{~h}+\text { drug }}$, cell number after $72 \mathrm{~h}$ of drug treatment $(10 \mathrm{~nm}$, $250 \mathrm{nM}) ; \mathrm{C}_{24 \mathrm{~h}+\text { drug }}$, cell number after $24 \mathrm{~h}$ of drug treatment $(10 \mathrm{~nm}, 250 \mathrm{nM}) ; \mathrm{C}_{72 \mathrm{~h}-\text { drug }}$, cell number after $72 \mathrm{~h}$ without drug treatment; $\mathrm{C}_{24 \mathrm{~h} \text {-drug }}$, cell number after $24 \mathrm{~h}$ without drug treatment.

Statistical calculations. Dose response curves were calculated using the Prism 3.03 software (GraphPad Software 
a

b

M[erbB2]

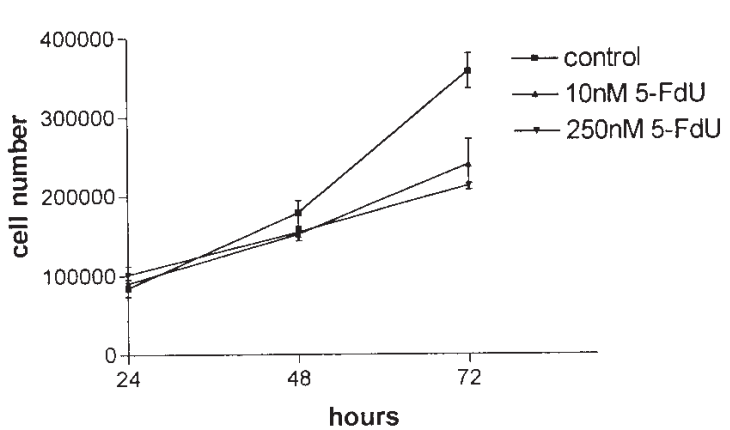

$\mathrm{C}$

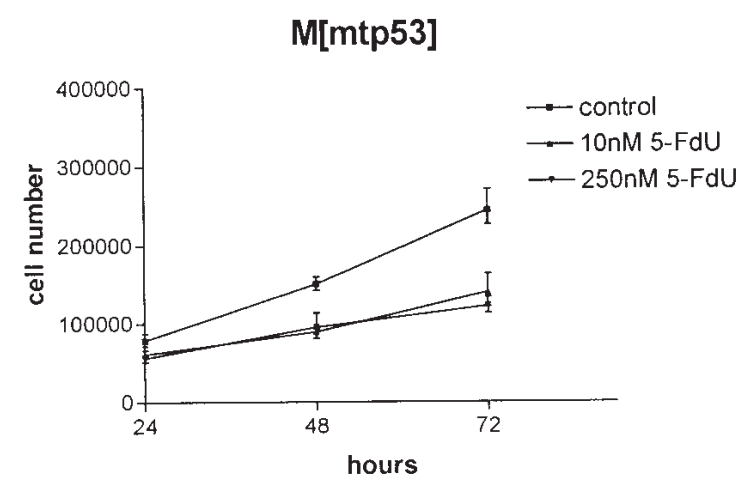

RF.M[erbB2]

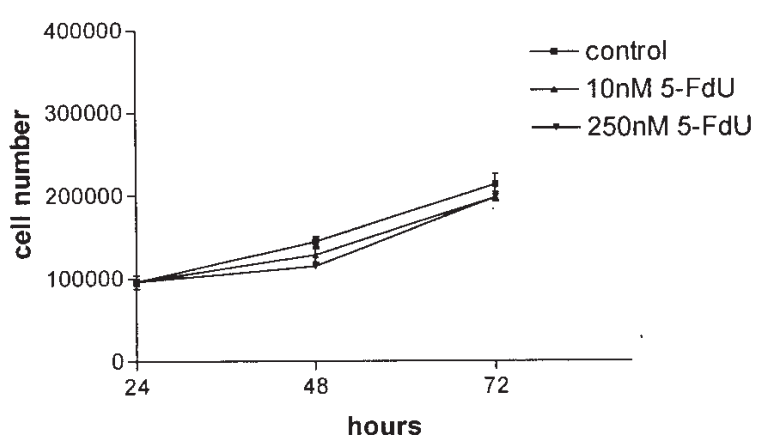

d

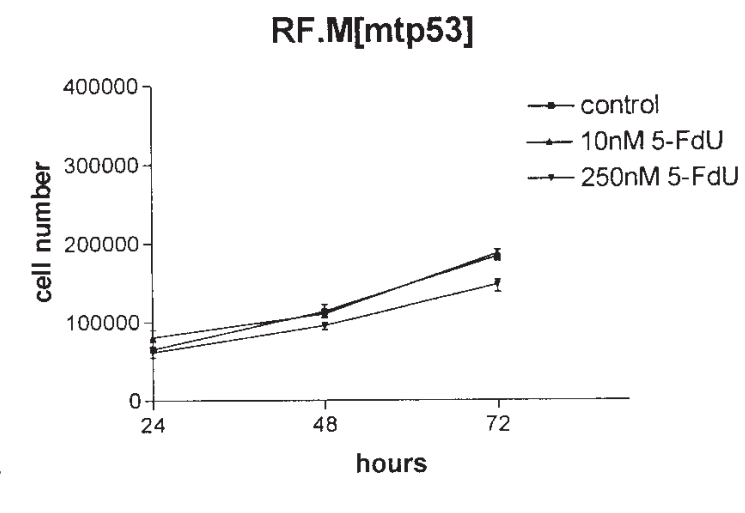

RA.M[erbB2]

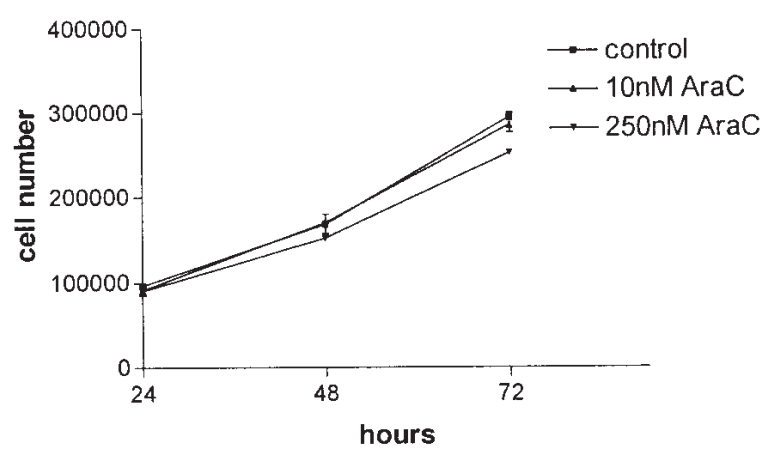

$\mathrm{h}$

g

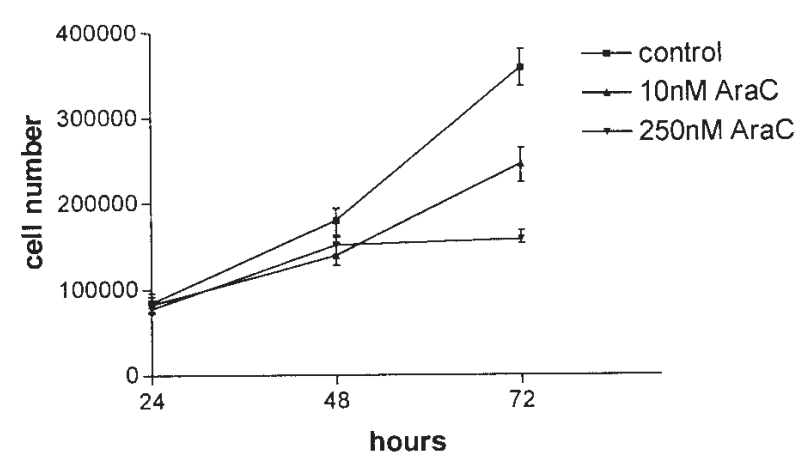

M[mtp53]

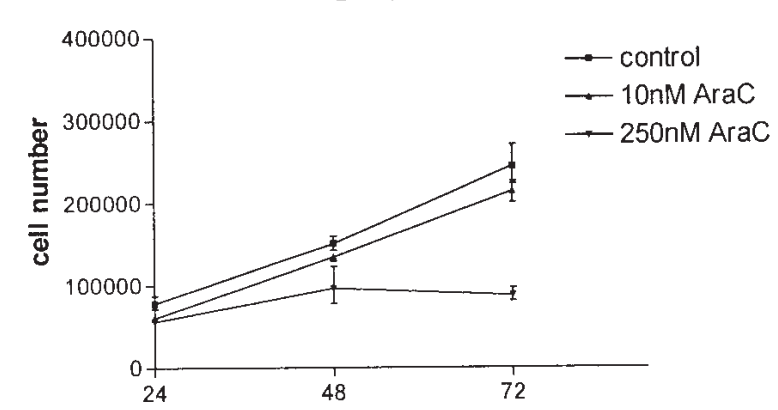

RA.M[mtp53]

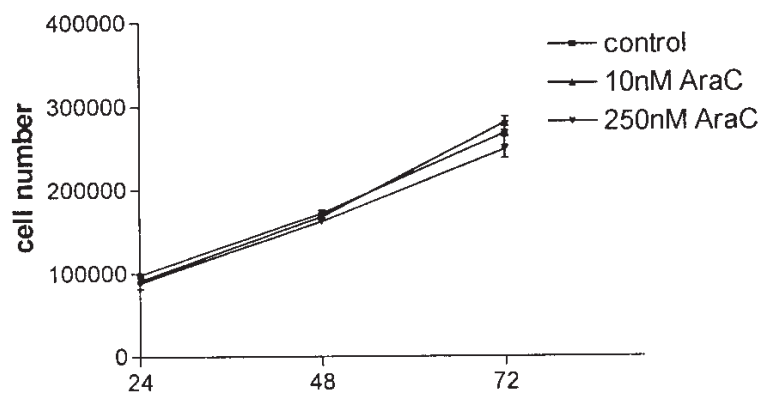



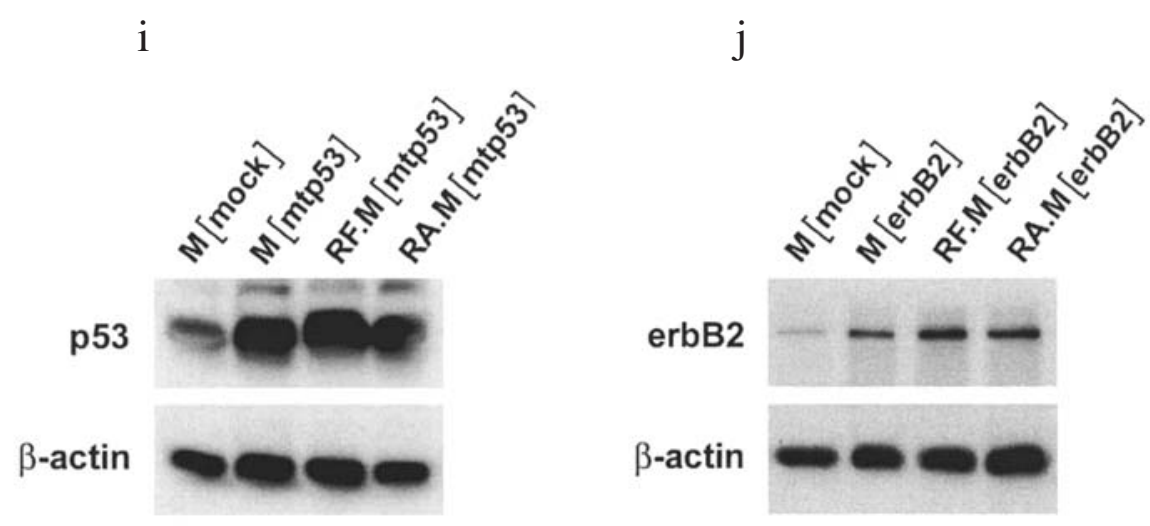

Figure 1. Response of the MCF-7 clone array to 5-FdUrd-mediated cell cycle inhibition and gene expression. M[erbB2] (a and e), RF.M[erbB2] (b), M[mtp53] (c and g), RF.M[mtp53] (d), RA.M[erbB2] (f) and RA.M[mtp53] (h) breast cancer cells were incubated with 10 and 250 nM 5-FdUrd (a-d), AraC (e-h) or solvent (control) for 24, 48 and $72 \mathrm{~h}$ when cell numbers were determined. Experiments were performed in triplicate and error bars indicate SD. MCF-7 cells were either transfected with empty vector [mock] (i and j), a dominant negative p53 mutant construct [mtp53] (i) or erbB2 cDNA [erbB2] (j) and the overexpression of mtp53 and ErbB2, also found in those clones that experienced long-term treatment with 5-FdUrd and AraC (post-transfection), was analyzed by Western blotting.

Inc., San Diego, CA, USA). Statistical differences were calculated using the unpaired t-test.

\section{Results}

The induction of specific chemoresistance. The low grade malignant breast cancer cell line MCF-7 harbors an intact p53, expresses ErbB2 only at a low level and is estrogen-receptor positive. For our studies, we generated an MCF-7 array consisting of clones overexpressing ErbB2 (M[erbB2]) and a mutated p53 construct (M[mtp53]) because this facilitates the study of the particular effects of these genes in the context of chemoresistance and the treatment with novel drugs.

$\mathrm{M}$ [erbB2] and $\mathrm{M}$ [mtp53] cells were long-term pretreated with 5-FdUrd or AraC to promote the acquisition of specific resistance. This yielded the 5-FdUrd-resistant clones RF.M[erbB2] and RF.M[mtp53] and the AraC-resistant clones RA.M[erbB2] and RA.M[mtp53], respectively. This clone array was utilized to evaluate the potential of resveratrol (and M5, see next paragraph) as the second line treatment option of chemoresistant breast cancer cells and to compare the activities of resveratrol and M5 in these MCF-7 derivatives.

RF.M[erbB2] cells were 74\% resistant and RF.M[mtp53] cells were $73 \%$ resistant to cell cycle inhibition mediated by $250 \mathrm{nM}$ 5-FdUrd (Fig. 1a-d). RA.M[erbB2] cells were 77\% resistant and RA.M[mtp53] cells were $72 \%$ resistant to cell cycle inhibition mediated by $250 \mathrm{nM}$ AraC (Fig. 1e-h).

The expression of ErbB2 and p53 was analyzed by Western blotting (Fig. 1i-j) and the cell duplication rates of $\mathrm{M}$ [mock], M[erbB2] and M[mtp53] cells were determined. Whereas ErbB2 overexpression accelerated the duplication rate $(22.6 \mathrm{~h})$, the expression of mutated p53 had no effect on the doubling rate $(29.2 \mathrm{~h})$ when compared to the control cells (30.3 h).

The inhibition of proliferation by resveratrol. In our investigations $\mathrm{M}$ [mock], M[erbB2] and M[mtp53] cells were exposed to 2, 10, 30 and $50 \mu \mathrm{M}$ resveratrol for 24,48 and $72 \mathrm{~h}$. Then the percentages of cell division progression were
Table I. Concentrations of resveratrol and M5 that inhibit $50 \%$ of proliferation in the MCF-7 clone array.

\begin{tabular}{lcc}
\hline Clones & $\begin{array}{c}\mathrm{I}_{\mathrm{p}} \mathrm{C}_{50}(\mu \mathrm{M}) \\
\text { of resveratrol }\end{array}$ & $\begin{array}{c}\mathrm{I}_{\mathrm{p}} \mathrm{C}_{50}(\mu \mathrm{M}) \\
\text { of M5 }\end{array}$ \\
\hline M[mock] & 9.2 & 7.5 \\
M[erbB2] & 7.8 & 1.1 \\
RF.M[erbB2] & 47.7 & 6.6 \\
RA.M[erbB2] & 6.5 & 6.6 \\
M[mtp53] & 27.0 & 6.9 \\
RF.M[mtp53] & 47.1 & 19.1 \\
RA.M[mtp53] & 13.5 & 1.5 \\
\hline
\end{tabular}

$\mathrm{M}$ [mock], M[erbB2], RF.M[erbB2], RA.M[erbB2], M[mtp53], RF.M[mtp53] and RA.M[mtp53] cancer cells were treated with 2, 10, 30 and $50 \mu \mathrm{M}$ resveratrol or M5 for 24,48 and $72 \mathrm{~h}$ and then the duplication times and the percentages of proliferation inhibition (compared to the untreated control) were calculated as described in Materials and methods. Thereafter, those concentrations of resveratrol and M5 (in $\mu \mathrm{M}$ ) that inhibited 50\% of proliferation ( $\mathrm{I}_{\mathrm{p}} \mathrm{C}_{50}$ values) were delineated from the drawings (Figs. 2 and 3).

calculated and blotted as linear graphs (Fig. 2a and b) to deduce the concentration of resveratrol which inhibited cell proliferation to $50 \%$ of the control $\left(\mathrm{I}_{\mathrm{p}} \mathrm{C}_{50}\right.$, Table $\left.\mathrm{I}\right)$. It has to be noted that this analysis specifically reflects the effects of drugs on the proliferation rate and not that of general drug toxicity $\left(\mathrm{IC}_{50}\right.$, which is a combination of cell cycle effects and cell death induction).

Compared to $\mathrm{M}[$ mock] cells, the response to resveratrol was markedly decreased in $\mathrm{M}[\mathrm{mtp} 53]$ cells $\left(\mathrm{I}_{\mathrm{p}} \mathrm{C}_{50} \mathrm{~s}: 9.2\right.$ and $27.0 \mu \mathrm{M}$, respectively), which is consistent with recent findings that resveratrol exerts its effects partly through p53 $(25,26)$. In contrast, in $\mathrm{M}$ [erbB2] cells the $\mathrm{I}_{\mathrm{p}} \mathrm{C}_{50}$ of resveratrol was $7.8 \mu \mathrm{M}$ and even $2 \mu \mathrm{M}$ resveratrol inhibited proliferation significantly. In the two 5-FdUrd-resistant clones, resveratrol 


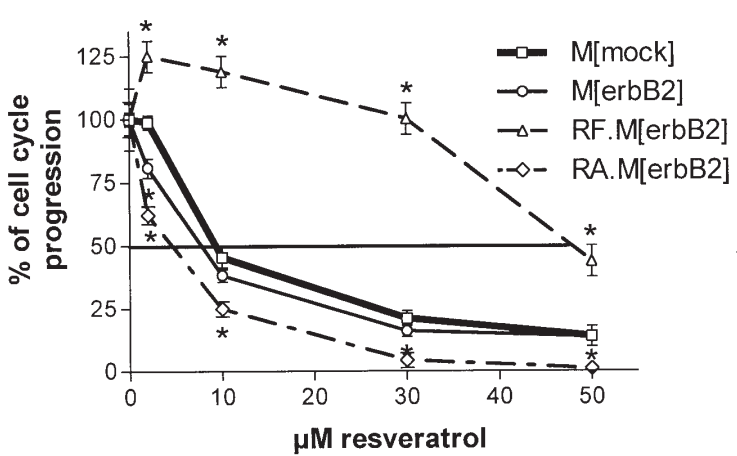

b

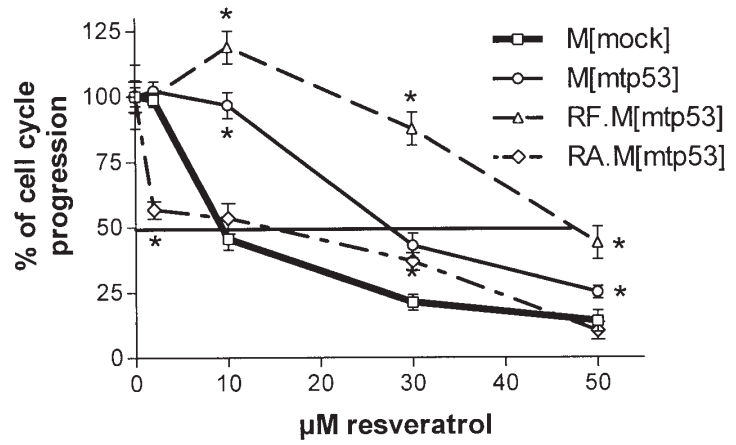

Figure 2. Growth inhibition of MCF-7 array clones upon treatment with resveratrol. M[mock], (a) M[erbB2] , RF.M[erbB2], RA.M[erbB2] and (b) $\mathrm{M}$ [mtp53], RF.M[mtp53], RA.M[mtp53] breast cancer cells were incubated with $2,10,30$ and $50 \mu \mathrm{M}$ resveratrol for 24,48 and $72 \mathrm{~h}$. Then cell numbers were determined and the percentages of cell division progression were calculated. "Significantly distinct inhibition of the cell cycle among identical resveratrol concentrations. Experiments were performed in triplicate and error bars indicate SD.

stimulated cell division at low doses $(2$ and $10 \mu \mathrm{M})$ and at higher resveratrol concentrations proliferation was more weakly inhibited as compared to the naïve cell clones $\left(\mathrm{I}_{\mathrm{p}} \mathrm{C}_{50} \mathrm{~S}\right.$ : $\mathrm{RF} \cdot \mathrm{M}[\mathrm{erbB} 2]=47.7 \mu \mathrm{M}, \mathrm{RF} \cdot \mathrm{M}[\operatorname{mtp} 53]=47.1 \mu \mathrm{M}$, compared to $\mathrm{M}[\mathrm{erbB} 2]=7.8 \mu \mathrm{M}, \mathrm{M}[\mathrm{mtp} 53]=27.0 \mu \mathrm{M})$. This observation is in agreement with earlier reports which demonstrated that higher doses $(>50 \mu \mathrm{M})$ of resveratrol generally inhibited cell growth in the estrogen receptor-positive and negative breast cancer cell lines, whereas lower doses $(<25 \mu \mathrm{M})$ stimulated cell growth in estrogen receptor-positive breast cancer cells $(4,27,28)$.

In the two AraC-resistant clones resveratrol was even more active than in the non-resistant $\mathrm{M}$ [erbB2] and M[mtp53] controls. This indicated that AraC pretreatment sensitized a cell cycle regulatory component which was targeted by resveratrol (Fig. 2a and b).

The inhibition of proliferation by 3, 4', 5-trimethoxystilbene (M5). M[erbB2], RF.M[erbB2], RA.M[erbB2], M[mtp53], RF.M[mtp53] and RA.M[mtp53] breast cancer cells were

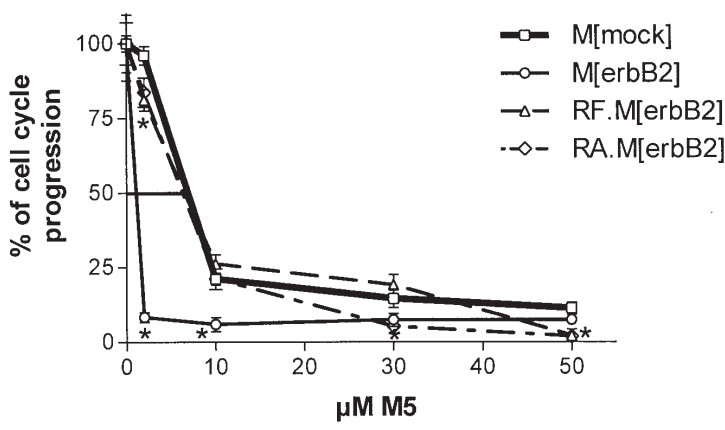

b

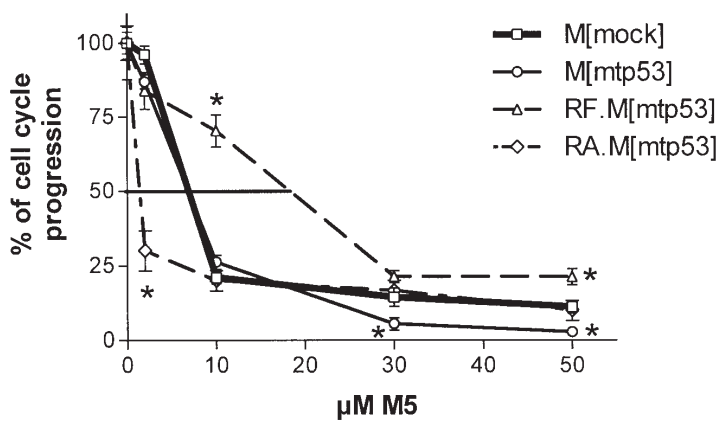

Figure 3. Growth inhibition of MCF-7 array clones upon treatment with M5. M[mock], (a) M[erbB2] , RF.M[erbB2], RA.M[erbB2] and (b) M[mtp53], RF.M[mtp53], RA.M[mtp53] breast cancer cells were incubated with 2, 10, 30 and $50 \mu \mathrm{M}$ M5 for 24, 48 and $72 \mathrm{~h}$. Then cell numbers were determined and the percentages of cell division progression were calculated. *Significantly distinct inhibition of the cell cycle among identical resveratrol concentrations. Experiments were performed in triplicate and error bars indicate SD.

treated with 2, 10, 30 and $50 \mu \mathrm{M}$ M5 for 24, 48 and $72 \mathrm{~h}$ and analyzed as described above (Fig. 3a and b). M5 inhibited the proliferation of $\mathrm{M}$ [mock] cells slightly more efficiently than resveratrol $\left(\mathrm{I}_{\mathrm{p}} \mathrm{C}_{50} \mathrm{~s}: 9.2\right.$ and $7.5 \mu \mathrm{M}$, respectively) and $\mathrm{M}$ [erbB2] cells with an $\mathrm{I}_{\mathrm{p}} \mathrm{C}_{50}$ of $1.1 \mu \mathrm{M}$. This proved that M5 targeted a component within the ErbB2 pathway and was independent of p53 because M5 was as active in M[mock] as in $\mathrm{M}$ [mtp53] cells. Moreover, resistance to 5-FdUrd did not reduce the effect of M5 in erbB2-overexpressing cells when compared to mock-control cells, although the efficiency of resveratrol was strongly reduced (by a factor of $\sim 5.2$ ). This demonstrates that M5 and resveratrol inhibited the cell cycle through different mechanisms, which was also verified in the clones expressing a mutated p53 because in M[mtp53], RF.M[mtp53] and RA.M[mtp53] cells the activity of M5 was $\sim 3.9-, \sim 2.5-$, and $\sim 8$.9-fold higher, respectively, than that of resveratrol. Resveratrol and M5 elicited a distinct response in AraC- or 5-FdUrd resistant cells. This underscores the specificity of the acquired type of resistance and the necessity to test novel anticancer agents in distinct genetic and chemoresistant backgrounds. 


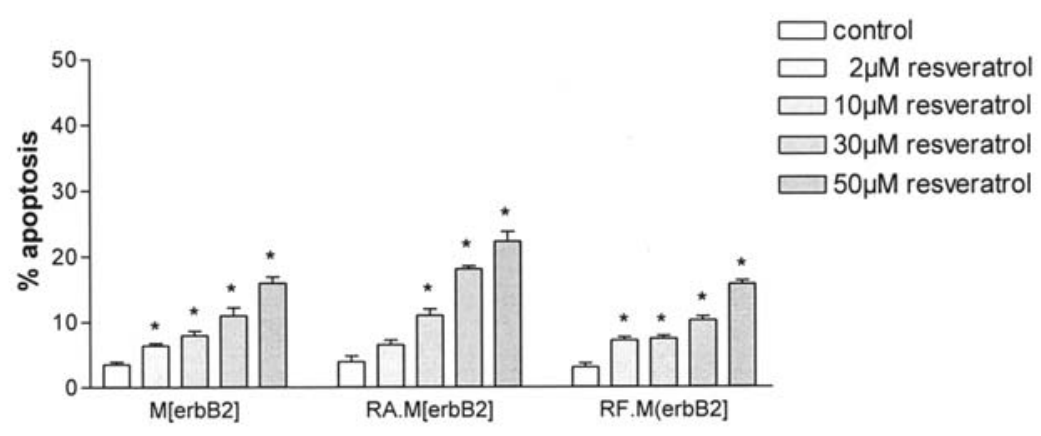

b

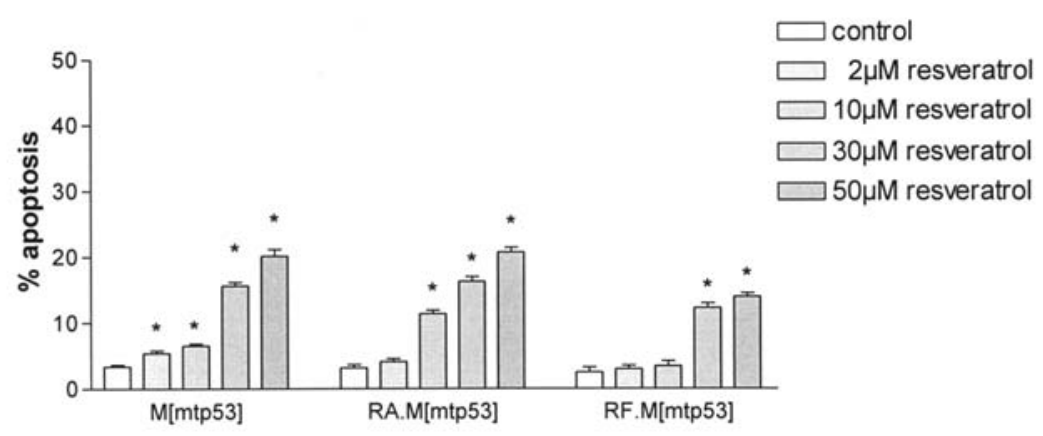

c

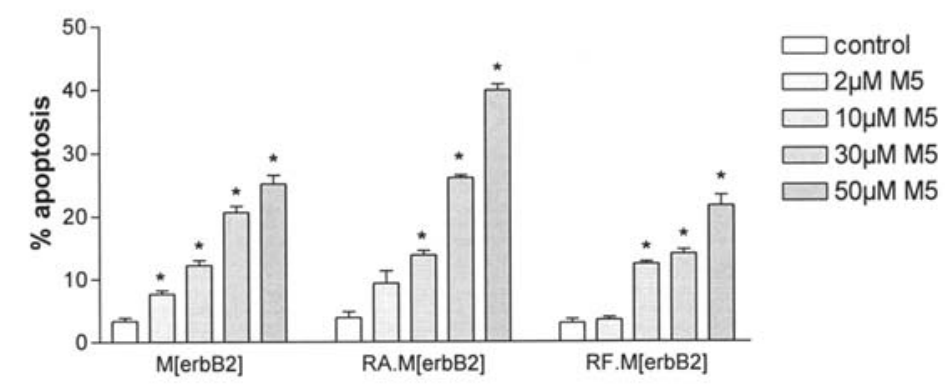

d

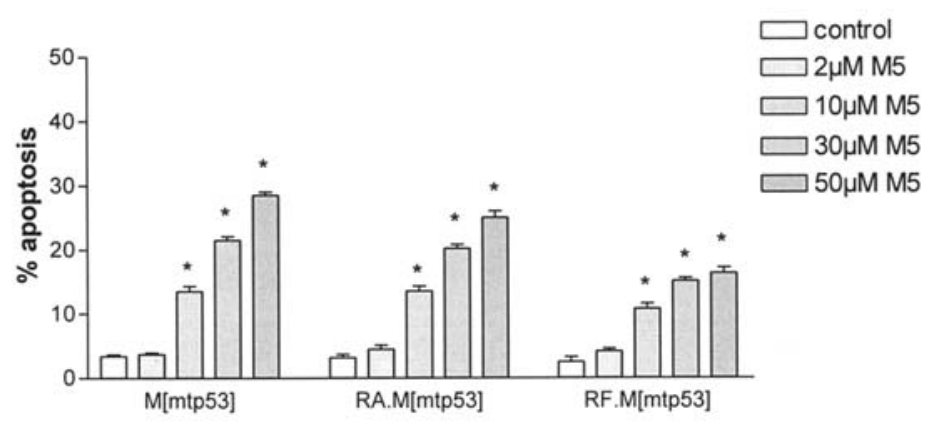

Figure 4. Resveratrol- and M5-induced apoptosis of MCF-7 clone array. Induction of apoptosis (a and c) in M[erbB2], RF.M[erbB2], RA.M[erbB2], and (b and d) in M[mtp53], RF.M[mtp53], RA.M[mtp53] clones was determined after treatment with 10 and $50 \mu \mathrm{M}$ resveratrol (a and b) or M5 (c and d) for $96 \mathrm{~h}$. Experiments were performed in triplicate and error bars indicate SD. *Significantly different values from untreated control cells $(\mathrm{p}<0.05)$ in the respective clone. 
Table II. Factors of apoptosis induction $\left(\mathrm{F}_{\text {apo }}\right)$ upon treatment of the MCF-7 clone array with resveratrol or M5.

\begin{tabular}{lcc}
\hline Clones & $\begin{array}{c}\mathrm{F}_{\text {apo }} \text { of } \\
\text { resveratrol }\end{array}$ & $\begin{array}{c}\mathrm{F}_{\text {apo }} \text { of } \\
\text { M5 }\end{array}$ \\
\hline M[erbB2] & 4.5 & 7.5 \\
RF.M[erbB2] & 5.1 & 7.1 \\
RA.M[erbB2] & 5.7 & 10.2 \\
M[mtp53] & 5.9 & 8.3 \\
RF.M[mtp53] & 5.6 & 6.5 \\
RA.M[mtp53] & 6.5 & 7.8 \\
\hline
\end{tabular}

M[mock], M[erbB2], RF.M[erbB2], RA.M[erbB2], M[mtp53], RF.M[mtp53] and RA.M[mtp53] cancer cells were treated with increasing concentrations of resveratrol or M5 for $96 \mathrm{~h}$ (only data derived from exposure to $50 \mu \mathrm{M}$ are shown). Then cells were stained with Hoechst 33258 and propidium iodide, analyzed and counted under a microscope connected to a DAPI filter and the factors of apoptosis induction above constitutive levels $\left(\mathrm{F}_{\text {apo }}\right.$, the controls were set as 1) were calculated.

The induction of apoptosis by resveratrol and M5. After 5FdUrd long-term pretreatment RF.M[erbB2] cells acquired $\sim 80 \%$ resistance and RF.M[mtp53] cells $\sim 78 \%$ resistance to $250 \mathrm{nM} 5$-FdUrd-induced apoptosis and after AraC longterm pretreatment RA.M[erbB2] cells acquired $\sim 90 \%$ resistance and RA.M[mtp53] cells $\sim 70 \%$ resistance to $250 \mu \mathrm{M}$ AraC (data not shown).

After treatment of the clone array with 2, 10, 30 and $50 \mu \mathrm{M}$ resveratrol or M5 for $96 \mathrm{~h}$, apoptosis was measured (Fig. 4a-d) and the factors of apoptosis induction $\left(\mathrm{F}_{\text {apo }}\right)$ were calculated (for $50 \mu \mathrm{M}$ resveratrol and M5, Table II). The two agents induced apoptosis dose-dependently and in all cell lines tested. At equimolar concentrations, M5 was more efficient than resveratrol, although the difference was marginal.

It is noteworthy that resveratrol and M5 induced apoptosis in the tested clones with similar efficiency (except in RA.M[erbB2] cells). Thus, regarding the apoptotic response, the clonal variation was minimal and this was in marked contrast to the cell cycle inhibitory activity of resveratrol and M5, which was highly diverse in these clones.

\section{Discussion}

The HER2/neu (ErbB2) status has been described as a prognostic factor in breast cancer, indicating that those patients whose cancer cells are positive for ErbB2 have a more aggressive disease. Breast cancers $(\sim 25 \%)$ overexpress ErbB2 and this causes increased cell division and the transformation of normal breast tissue into malignant cancer cells. Since MCF-7 cells express ErbB2 only at a low level, an erbB2 cDNA construct was stably transfected to study erbB2specific drug effects.

The p53 tumor suppressor regulates the repair of damaged DNA, whereas the mutated p53 fails to maintain intact DNArepair, DNA-integrity and checkpoint control and therefore, the persistence of damaged DNA supports the development of malignant cells (29). In general, p53 mutations occur in $>50 \%$ of all tumors including breast cancer. Hence, a dominant negative p53 mutant was transfected into MCF-7 breast cancer cells, which otherwise harbor intact p53, to enforce the acquisition of chemoresistance.

We tested both individual oncogenic conditions (the overexpression of ErbB2 and mutated p53) in MCF-7 cells regarding the responsiveness to resveratrol. Resveratrol is a naturally-occurring, biologically-active phytochemical commonly found in grapes, berries and red wine (17). Experiments in different cell types and isolated subcellular systems implicate a variety of mechanisms in the pharmacological activity of resveratrol. These mechanisms include inhibition of the transcription factor $\mathrm{NF}-\kappa \mathrm{B}$, cytochrome P450 isoenzyme CYP1A1 and cyclooxygenase (COX) enzymes. Resveratrol has also been shown to induce Fasmediated and p53-dependent apoptosis. Furthermore, it possesses antioxidant, anti-angiogenic and anti-estrogenic properties $(2,4-8,18)$. Hence, resveratrol is currently investigated as a potential cancer chemopreventive agent. Sinclair et al show that resveratrol may increase the cell survival of $C$. elegans by stimulating the SIRT1-dependent deacetylation of $\mathrm{p} 53$, indicating that resveratrol has obtained a new role in anti-aging research, besides its effects as a radical scavenger (25). Methoxylated resveratrol analogues were demonstrated to be more potent than resveratrol in inducing apoptosis (19), but most effects are still unknown and have yet to be investigated. Therefore, the methoxylated resveratrol analogue M5 was also investigated in the MCF-7 clone array to study the structure-activity relationship regarding apoptosis induction and cell cycle inhibition.

In an erbB2-overexpressing background resveratrol remained as effective as in $\mathrm{M}$ [mock] control cells, whereas M5 inhibited the cell cycle with $\sim 6.8$ fold higher efficiency in $\mathrm{M}$ [erbB2] cells than in M[mock] cells. Since erbB2overexpression accelerated the cell cycle and supported the activity of M5 (however not that of resveratrol), this indicated that M5 targeted a component downstream of ErbB2 signaling possibly at the level of cell cycle control.

Transfection of the p53 mutant cDNA did not alter the proliferation rate of $\mathrm{M}[\mathrm{mtp53}]$ cells. However, it caused an $\sim 3$-fold decreased response to resveratrol-induced cell cycle inhibition, which was in agreement with earlier reports demonstrating that the effect of resveratrol is p53-dependent $(25,26)$. In contrast, M5 did not require p53 for its activity.

Therefore, resveratrol as well as M5 inhibited proliferation dependent on the cells genetic background of the cells (i.e. resveratrol depended on p53 and M5 depended on ErbB2) and this indicated that the cell cycle inhibitory mechanisms of resveratrol and M5 were different from each other, or that M5 exerted additional activities.

As a second endpoint which is relevant for anticancer activity, apoptosis induction was analyzed. Huang et al found that resveratrol-induced apoptosis occurred only in cells expressing wild-type p53, but not in p53-deficient cells (26). Notably, our investigations showed that resveratrol induced apoptosis in p53-mutated breast cancer cells as well as in ErbB2-overexpressing cells. This proved that the mutation of p53 interfered with check points controlling the cell cycle, but 
not with the apoptotic mechanisms, which demonstrates that cell cycle inhibition and apoptosis induction are independent and disconnected from each other (30). Compared to resveratrol M5 exhibited a higher proapoptotic activity. Similarly, resveratrol and M5 induced cell death in M[mtp53] and M[erbB2] cells. These observations support the notion that resveratrol inhibited cell cycle progression through a mechanism which was different from that of M5, whereas the apoptosis-inducing mechanism of resveratrol and M5 were most likely the same.

Although a broad range of human health benefits have been reported for resveratrol, its effects on the cell cycle and apoptosis in chemoresistant breast cancer cells are unknown. Hence, our investigations focused on the activity of resveratrol and M5 in MCF-7 breast cancer clones which acquired specific resistance to 5-FdUrd and AraC. Due to the structural similarity to estrogen resveratrol is suspected of partly functioning by modulating the activity of the estrogen receptor. Furthermore, the radical scavenging property of resveratrol was reported to chelate the tyrosyl radical attached to ribonucleotide reductase, which is required for its activation (31). Thus, resveratrol directly interferes with the NTP and dNTP supply, DNA synthesis and the cell cycle. Resistance to 5-FdUrd was shown to involve nucleotide metabolizing enzymes and since resveratrol targets ribonucleotide reductase, which is a central player in this metabolic pathway, the activity of resveratrol may become absorbed upon the affection of this pathway, as it was observed in the present experiments herein.

Pretreatment with AraC affected cellular mechanisms which were clearly different from mechanisms affected by 5FdUrd treatment, because resveratrol maintained its activity in the AraC-resistant clones but not in the 5-FdUrd-resistant clones.

Although M5 exhibited improved activity in ErbB2overexpressing cells compared to mock-control cells, this advantage was lost upon the acquisition of 5-FdUrd- and AraC-resistance in this genetic background. Therefore, besides the affection of distinct cellular components (see above), similar mechanisms seemed to be addressed by 5 -FdUrd- and AraC-resistance.

This suggested that resistance to 5-FdUrd and AraC also involved component(s) within the very pathway that was activated by ErbB2-overexpression in the first place. 5-FdUrdand AraC-induced resistance were reported to inflict a blocking of first-step phosphorylation of the nucleosides by thymidine or deoxycytidine kinase $(30,32)$ and therefore, ErbB2 may have contributed to the availability of dNTPs for subsequent incorporation into replicating DNA, which was supported by the fact that M[erbB2] cells showed a considerably accelerated proliferation rate.

Cell cycle inhibition by M5 was independent of p53, yet the activity of M5 was reduced in FdU-pretreated RF.M[mtp53] cells, whereas AraC-pretreatment sensitized RA.M[mtp53] cells to M5. This underscores that the genotype together with the chemoresistant phenotype dramatically influences drug action.

Notably, resveratrol and M5 maintained the apoptogenic potential in 5-FdUrd- and AraC-resistant clones overexpressing ErbB2 or mtp53. Either the acquired resistance to 5-FdUrd- induced apoptosis was only a matter of the abrogated activation of 5-FdUrd to 5-UMP [through the loss of function of thymidine or deoxycytidine kinase, (32-34)] and therefore, 5-FdUrd-resistance may have left apoptotic mechanisms per se unaffected; or, resveratrol and M5 may have employed apoptotic mechanisms which were different from those triggered by 5-FdUrd or AraC.

We intend to add further resistance phenotypes to this array because we think that the MCF-7 clones were successfully used as a tool to elucidate the activity spectrum of novel putative anticancer agents. The findings of this study warrant testing resveratrol and M5 in chemoresistant animal models.

\section{Acknowledgements}

This work was supported by the Unruhe Privatstiftung (given to G.K.).

\section{References}

1. http://www.breastcancer.org/cmn_who_indrisk.html

2. Le Corre L, Chalabi N, Delort L, Bignon YJ and Bernard-Gallon DL: Resveratrol and breast cancer chemo-prevention: molecular mechanisms. Mol Nutr Food Res 49: 462-471, 2005.

3. Bowers JL, Tyulmenkov W, Jernigan SC and Klinge CM: Resveratrol acts as a mixed agonist/antagonist for estrogen receptors alpha and beta. Endocrinology 141: 3657-3667, 2000.

4. Gehm BD, McAndrews JM, Chien PY and Jameson JL: Resveratrol, a polyphenolic compound found in grapes and wine, is an agonist for the estrogen receptor. Proc Natl Acad Sci USA 94: 14138-14143, 1997.

5. Fauconneau B, Waffo-Teguo P, Huguet F, Barrier L, Decendit A, et al: Comparative study of radical scavenger and antioxidant properties of phenolic compounds from Vitis vinifera cell cultures using in vitro tests. Life Sci 61: 2103-2110, 1997.

6. Stojanovic S, Sprinz H and Brede O: Efficiency and mechanism of the antioxidant action of trans-resveratrol and its analogues in the radical liposome oxidation. Arch Biochem Biophys 391: 79-89, 2001.

7. Dong Z: Molecular mechanism of the chemopreventive effect of resveratrol. Mutat Res 523-524: 145-150, 2003.

8. Jang M, Cai L, Udeani GO, Slowing KV, Thomas CF, et al: Cancer chemopreventive activity of resveratrol, a natural product derived from grapes. Science 275: 218-220, 1997.

9. Damianaki A, Bakogeorgou E, Kampa M, Notas G, Hatzoglou A, et al: Potent inhibitory action of red wine polyphenols on human breast cancer cells. J Cell Biochem 78: 429-441, 2000.

10. Gautam SC, Xu YX, Dumaguin M, Janakiraman N and Chapman RA: Resveratrol selectively inhibits leukemia cells: a prospective agent for ex vivo bone marrow purging. Bone Marrow Transplant 25: 639-645, 2000.

11. Mitchell SH, Zhu W and Young CY: Resveratrol inhibits the expression and function of the androgen receptor in LNCP prostate cancer cells. Cancer Res 59: 5892-5895, 1999.

12. Pozo-Guisado E, Alvarez-Barrientos A, Mulero-Navarro S, Santiago-Josefat B and Fernandez-Salguero PM: The antiproliferative activity of resveratrol results in apoptosis in MCF-7 but not in MDA-MB-231 human breast cancer cells: cellspecific alteration of the cell cycle. Biochem Pharmacol 64: 1375-1386, 2002

13. Schneider Y, Vincent F, Duranton B, Badolo L, Gosse F, et al: Anti-proliferative effect of resveratrol, a natural component of grapes and wine, on human colonic cancer cells. Cancer Lett 158: 85-91, 2000 .

14. Zhou HB, Yan Y, Sun YN and Zhu JR: Resveratrol induces apoptosis in human esophageal carcinoma cells. World J Gastroenterol 9: 408-411, 2003.

15. Ragione FD, Cucciolla V, Borriello A, Pietra VD, Racioppi L, et al: Resveratrol arrests the cell division cycle at S/G2 phase transition. Biochem Biophys Res Commun 250: 53-58, 1998.

16. Fontecave M: Ribonucleotide reductases and radical reactions. Cell Mol Life Sci 54: 684-695, 1998.

17. Burns J, Yokota T, Ashihara H, Lean ME and Crozier A: Plant foods and herbal sources of resveratrol. J Agric Food Chem 50: 3337-3340, 2002. 
18. Fang JG, Lu M, Chen ZH, Zhu HH, Li Y, et al: Antioxidant effects of resveratrol and its analogues against the free-radicalinduced peroxidation of linoleic acid in micelles. Chem Eur J 8: 4191-4198, 2002.

19. Tolomeo M, Grimaudo S, Di Christina A, Roberti M, Pizzirani D, et al: Pterostilbene and 3'-hydroxypterostilbene are effective apoptosis-inducing agents in MDR and BCR-ABL-expressing leukemia cells. Int J Biochem Cell Biol 37: 1709-1726, 2005.

20. Venditti JM, Wesley RA and Plowman J: Current NCI preclinical antitumor screening in vivo: results of tumor panel screening, 1976-1982, and future directions. Adv Pharmacol Chemother 20: 1-20, 1984

21. Weinstein JN, Myers TG, O'Connor PM, Friend SH, Fornace AJ Jr, Kohn KW, Fojo T, Bates SE, Rubinstein LV, Anderson NL, Buolamwini JK, van Osdol WW, Monks AP, Scudiero DA, Sausville EA, Zaharevitz DW, Bunow B, Viswanadhan VN, Johnson GS, Wittes RE and Paull KD: An information-intensive approach to the molecular pharmacology of cancer. Science 275: 343-349, 1997.

22. Murias M, Handler N, Erker T, Pleban K, Ecker G, et al: Resveratrol analogues as selective cyclooxygenase-2 inhibitors: synthesis and structure-activity relationship. Bioorg Med Chem 12: 5571-5578, 2004.

23. Grusch M, Polgar D, Gfatter S, Leuhuber K, Huettenbrenner S, et al: Maintenance of ATP favours apoptosis over necrosis triggered by benzamide riboside. Cell Death Differ 9: 169-178, 2002 .

24. Huettenbrenner S, Maier S, Leisser C, Polgar D, Strasser S, et al: The evolution of cell death programs as prerequisites of multicellularity. Mutat Res 543: 235-249, 2003.

25. Howitz KT, Bitterman KJ, Cohen HY, Lamming DW, Lavu S, Wood JG, Zipkin RE, Chung P, Kisielewski A, Zhang LL, Scherer B and Sinclair DA: Small molecule activators of sirtuins extend Saccharomyces cerevisiae lifespan. Nature 425: 191196, 2003.

26. Huang C, Ma WY, Goranson A and Dong Z: Resveratrol suppresses cell transformation and induces apoptosis through a p53-dependent pathway. Carcinogenesis 20: 237-242, 1999.
27. Nakagawa H, Kiyozuka Y, Uemura Y, Senzaki H, Shikata N, et al: Resveratrol inhibits human breast cancer cell growth and may mitigate the effect of linoleic acid, a potent breast cancer cell stimulator. J Cancer Res Clin Oncol 127: 258-264, 2001.

28. Basly JP, Marre-Fournier F, Le Bail JC, Habrioux G and Chulia AJ: Estrogenic/anti-estrogenic and scavenging properties of (E)- and (Z)-resveratrol. Life Sci 66: 769-777, 2000.

29. Bottomley RH and Condit PT: Cancer families. Cancer Bull 20: 22-24, 1968.

30. Maier S, Strasser S, Saiko P, Leisser C, Sasgary S, Grusch M, Madlener S, Bader Y, Hartmann J, Schott H, Mader RM, Szekeres T, Fritzer-Szekeres M and Krupitza G: Analysis of mechanisms contributing to AraC-mediated chemoresistance and re-establishment of drug sensitivity by the novel heterodinucleoside phosphate 5-FdUrd-AraC. Apoptosis 11: 427-440, 2006.

31. Fontecave M, Lepoivre M, Elleingand E, Gerez C and Guittet O: Resveratrol, a remarkable inhibitor of ribonucleotide reductase. FEBS Lett 421: 277-279, 1998.

32. Agarwal RP, Han T and Fernandez M: Reduced cellular transport and activation of fluoropyrimidine nucleosides and resistance in human lymphocytic cell lines selected for arabinosylcytosine resistance. Biochem Pharmacol 61: 39-47, 2001.

33. Bhalla K, Nayak R and Grant S: Isolation and characterization of a deoxycytidine kinase-deficient human promyelocytic leukemic cell line highly resistant to 1-beta-D- arabinofuranosylcytosine. Cancer Res 44: 5029-5037, 1984.

34. Strasser S, Maier S, Leisser C, Saiko P, Madlener S, Bader Y, Bernhaus A, Gueorguieva M, Richter S, Mader RM, Wesierska-Gadek J, Schott H, Szekeres T, Fritzer-Szekeres M and Krupitza G: 5-FdUrd-AraC heterodinucleoside re-establishes sensitivity in 5-FdUrd- and AraC-resistant MCF-7 breast cancer cells overexpressing ErbB2. Differentiation 74: 488498, 2006. 